\title{
The effects of phenytoin on phenobarbitone and primidone metabolism
}

\author{
D G L A M B I E A N D R H JOH N S O N \\ from the Wellington Clinical School of Medicine, Wellington, New Zealand
}

SUMMARY Serum concentrations of primidone and its metabolites-phenobarbitone and phenylethylmalonamide-were measured in 40 epileptic patients receiving treatment with primidone alone or primidone plus phenytoin. Serum phenobarbitone concentrations were also measured in 100 patients receiving phenobarbitone, alone or with phenytoin. Patients receiving either phenobarbitone or primidone in combination with phenytoin showed raised serum phenobarbitone concentrations. Phenytoin also caused raised phenylethylmalonamide concentrations in patients on primidone.

Primidone is a desoxybarbiturate which is widely used in the treatment of epilepsy. It is converted in the body to two major metabolites-phenobarbitone and phenylethylmalonic acid (PEMA). Primidone exerts its anticonvulsant effect at least partly via oxidation to phenobarbitone. In addition, PEMA has been shown to have anticonvulsant activity in rats. ${ }^{1}$ Since primidone is converted in vivo to these two active metabolites, whose anticonvulsant properties may differ, variations in the metabolism of the drug between different individuals are likely to be of therapeutic importance. Fincham et $a l^{2}$ found higher concentrations of phenobarbitone in patients receiving phenytoin and primidone, compared to patients on primidone only, and suggested that phenytoin induces primidone metabolism to phenobarbitone. However, in a previous study ${ }^{3}$ we found that an increase in the serum concentration of phenytoin caused an increase in the serum phenobarbitone concentration in patients receiving either phenobarbitone or primidone. This suggests that the action of phenytoin is directly on phenobarbitone rather than on metabolism of primidone.

To establish the nature of the interaction between phenytoin and primidone we have carried out a study in epileptic patients of the effects of

Address for reprint requests: Dr DG Lambie, Wellington Clinical School of Medicine, Wellington, New Zealand.

Accepted 3 October 1980 phenytoin on primidone metabolism, including metabolism of primidone to PEMA, which has not been studied previously. The effect of phenytoin on phenobarbitone serum concentrations in patients receiving primidone has been compared to the effect in patients receiving phenobarbitone.

\section{Patients and methods}

One hundred and forty epileptic patients receiving anticonvulsant therapy, aged 16 to 66 years (mean 42 years), were studied. All patients were receiving either phenobarbitone or primidone and 109 patients were in addition receiving phenytoin. The drug regimes that patients were receiving are summarised in the table. Blood samples for anticonvulsant analysis

Table Anticonvulsants received by the patients in this study

\begin{tabular}{lccc}
\hline & Phenobarbitone & Primidone & Total \\
\hline Single therapy & 22 & 9 & 31 \\
With phenytoin & 78 & 31 & 109 \\
Total & 100 & 40 & 140 \\
\hline
\end{tabular}

were obtained from patients between two and four hours after the last drug dose. Concentrations of phenytoin, phenobarbitone and primidone were measured in all patients by gas chromatography (Goudie and Burnett). ${ }^{4}$ Also, in the patients receiving primidone, serum PEMA concentrations were measured by a gas chromatographic method. ${ }^{1}$ 


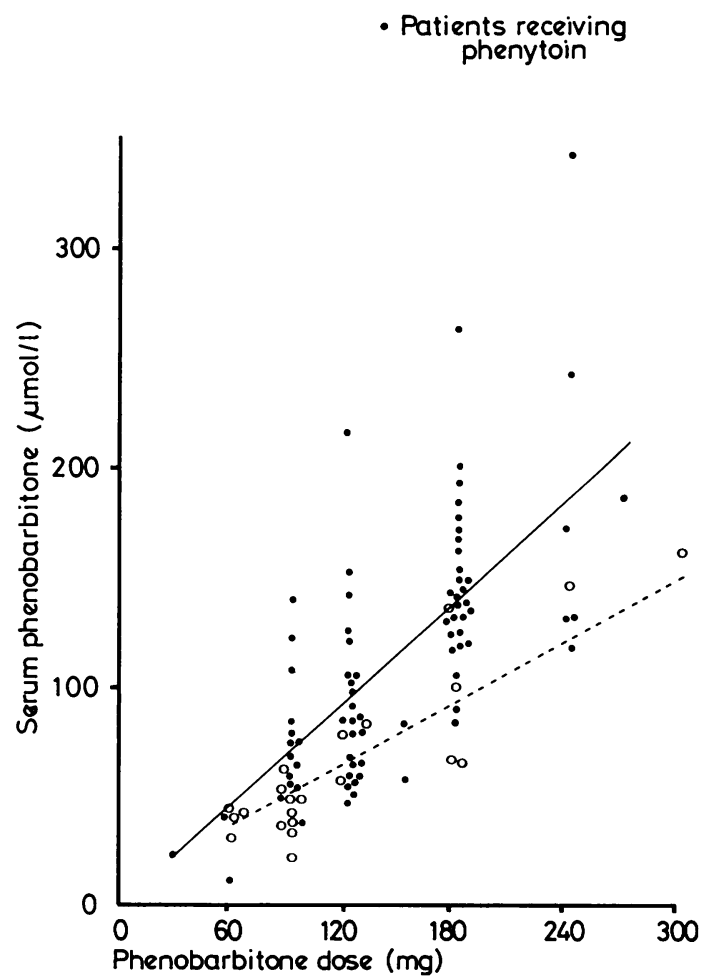

Fig. 1a

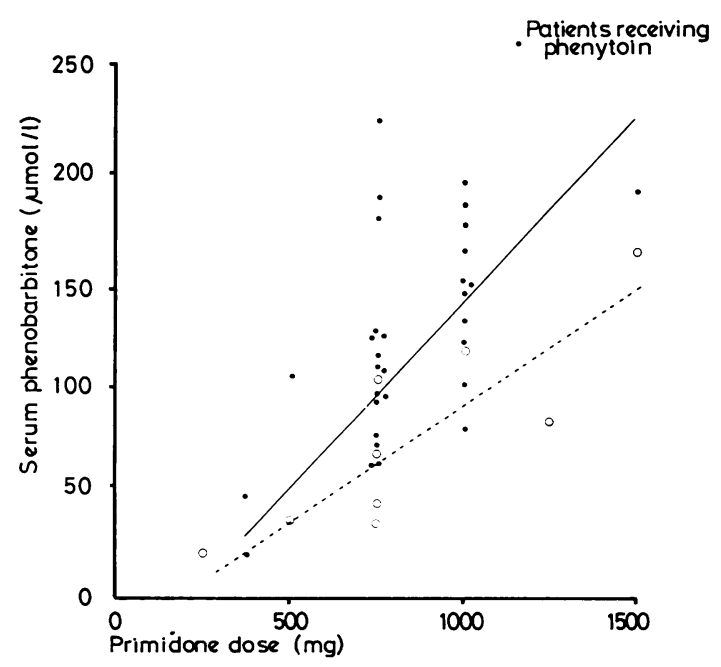

Fig. 1b

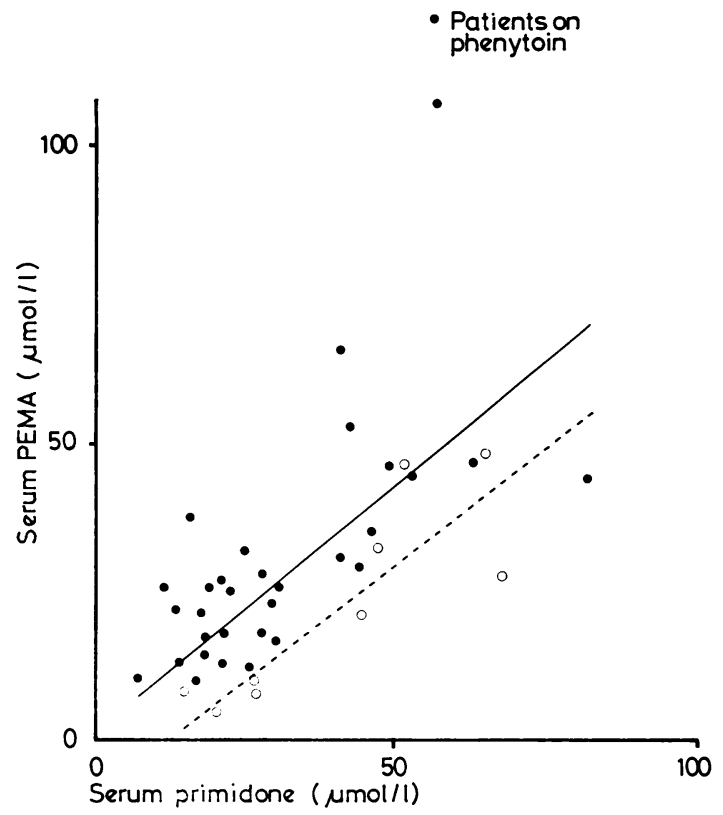

Fig. 1c

Fig 1 (a) Serum phenobarbitone concentrations in 22 patients receiving phenobarbitone alone and 78 patients receiving combined therapy with phenytoin and phenobarbitone. The regression line for patients on phenytoin is shown as a solid line and the regression line for patients on phenobarbitone alone is shown as an interrupted line. The slope of the regression line is significantly greater $(t=2 \cdot 19, p<0 \cdot 05)$ in patients receiving phenytoin. (b) Serum phenobarbitone concentrations in 19 patients receiving primidone alone and 52 patients receiving combined therapy with phenytoin and primidone. (c) Serum concentrations of phenylethylmalonamide (PEMA) in relation to primidone concentrations, in 9 patients receiving primidone alone and 31 patients receiving primidone and phenytoin. The PEMA/primidone ratio is significantly higher $(p<0.005)$ in patients on phenytoin.

\section{Results}

Serum concentrations of phenobarbitone in patients receiving phenobarbitone alone and patients receiving combined therapy with phenytoin are shown in fig 1a. Patients receiving phenytoin showed higher serum concentrations of phenobarbitone-the slope of the regression line for serum concentrations against dose was significantly greater $(t=2 \cdot 19, \mathrm{p}<0.05)$ in patients receiving phenytoin. As shown in fig $1 \mathrm{~b}$, patients 
receiving primidone alone had generally lower serum concentrations of phenobarbitone than patients on combined therapy, but in this case there was no significant difference between the slopes of the regression lines for serum concentrations against dose. The phenobarbitone/ primidone ratio was, however, significantly higher $(p<0.05)$ in patients on phenytoin-mean of $4.5 \pm 2.3 \mathrm{SD}$ in patients on phentoin compared with $2 \cdot 7 \pm 1 \cdot 1 \mathrm{SD}$ in patients on primidone alone. In 22 patients who were receiving a standard dose of $300 \mathrm{mg}$ phenytoin daily there was a trend towards a higher phenobarbitone/primidone ratio with increasing phenytoin concentration, and this just failed to reach significance $(r=0 \cdot 399$, $\mathrm{p}<0 \cdot 1)$.

Serum concentrations of PEMA were measured in patients receiving primidone. The relationship between serum concentrations of primidone and PEMA is shown in fig 1c. The PEMA/primidone ratio was significantly increased in patients on phenytoin $(t=3.04, \mathrm{p}<0.005)$-patients on phenytoin showed a mean ratio of $1.05 \pm 0.51$ compared with a mean ratio of $0.59 \pm 0.21 \mathrm{SD}$ for patients on primidone alone. There was also some evidence for an effect of primidone itself in increasing the PEMA/primidone ratio. Multiple regression analysis showed that the PEMA/ primidone ratio $=0.295+(0.400 \times$ primidone dose $)$ $+(1.30 \times$ phenytoin dose $)$ where drug doses are total grams received daily; however, although the partial correlation coefficient was significant for the plenytoin dose $(p<0.05)$ it did not reach significance for the primidone dose $(p<0 \cdot 1)$.

\section{Discussion}

Many patients receive combined therapy of phenytoin with primidone or phenobarbitone and interactions between these drugs may be of therapeutic significance. This study shows that phenytoin causes raised serum concentrations of phenobarbitone. This effect may be related to the phenytoin concentration since, in a previous study, ${ }^{3}$ we found that increasing the phenytoin concentration produced an increase in phenobarbitone concentrations in patients on combined therapy. An increase in phenobarbitone serum concentrations after addition of phenytoin has previously been documented in children. ${ }^{5}$

Other workers have shown an increase in the phenobarbitone/primidone ratio in patients on phenytoin $^{26}$ and have suggested that phenytoin induces the liver enzyme system responsible for the oxidation of primidone to phenobarbitone. Reynolds, ${ }^{7}$ however, proposed that the action of phenytoin was on phenobarbitone metabolism; our finding that the effect of phenytoin on phenobarbitone concentrations was at least as great in patients receiving phenobarbitone to that in patients receiving primidone supports a mechanism involving a direct action on phenobarbitone. Enzyme induction might nonetheless have an effect on primidone metabolism. Phenytoin and possibly also primidone increase PEMA levelsthis may be via induction of primidone metabolism to PEMA, although other mechanisms are possible including inhibition of excretion or displacement from tissue binding sites.

The effect of phenytoin in increasing serum concentrations of phenobarbitone would be expected to increase the therapeutic effect, and this may at least partly account for the apparent synergistic effect when these drugs are given simultaneously. The clinical importance of the interaction of phenytoin with primidone will depend on the relative therapeutic importance of primidone and its metabolites. If primidone itself has important anticonvulsant activity, it would be expected that administration of phenytoin may lower the therapeutic effect of the drug. However, Olesen and $\mathrm{Dam}^{8}$ found no difference between the clinical effectiveness of phenobarbitone and primidone and suggested that the anticonvulsant activity of primidone is simply due to derived phenobarbitone. It might therefore be expected that combined therapy (phenytoin with primidone) would produce a synergistic effect due to increase in serum concentrations of phenobarbitone. It remains possible, however, that primidone exerts an important anticonvulsant effect of its owna recent study ${ }^{9}$ found primidone to be a superior anticonvulsant to phenobarbitone in the control of major seizures-and in that case a reduction in primidone levels due to interaction with phenytoin could reduce effectiveness.

D G Lambie was supported by Reckitt and Colman (NZ) Ltd.

\section{References}

1 Baumel JP, Gallagher BB, Mattson RH. Phenylethylmalonamide (PEMA). An important metabolite of primidone. Arch Neurol 1972; 27:34-41.

2 Fincham RW, Schottelius DD, Sah AL. The influence of diphenylhydantoin on primidone metabolism. Arch Neurol 1973; 30:259-62.

3 Lambie DG, Johnson RH, Nanda RN, Shakir RA. Therapeutic and pharmacokinetic effects of 
increasing phenytoin in chronic epileptics on multiple drug therapy. Lancet 1976; i:386-9.

4 Goudie JH, Burnett D. A gas-chromatographic method for the simultaneous determination of phenobarbitone, primidone and phenytoin in serum using a nitrogen detector. Clin Chim Acta 1973; 43:423-9.

5 Morselli PL, Rizzo M, Garattini S. Interaction between phenobarbital and diphenylhydantoin in animals and in epileptic patients. Proc Acad Sci 1971; 179: 88-107.

6 Callaghan N. Feely M, Duggan F, O'Callaghan M, Seldrup J. The effect of anticonvulsant drugs which induce liver enzymes on derived and ingested phenobarbitone levels. Acta Neurol Scand
1977; 56:1-6.

7 Reynolds EH, Fenton G, Fenwick P, Johnson $A L$, Laundy $M$. Interaction of phenytoin and primidone. Br Med J 1975; 2:594-5.

8 Olesen OV, Dam M. The metabolic conversion of primidone (mysoline) to phenobarbitone in patients under long-term treatment. Acta Neurol Scand 1967; 43:348-56.

9 Oxley J, Hebdidge S, Laidlaw J, Wadsworth J, Richens A. A comparative study of phenobarbitone and primidone in the treatment of epilepsy. In: Johannessen SI et al (ed) Antiepileptic Therapy: Advances in Drug Monitoring. New York: Raven Press 1980. 